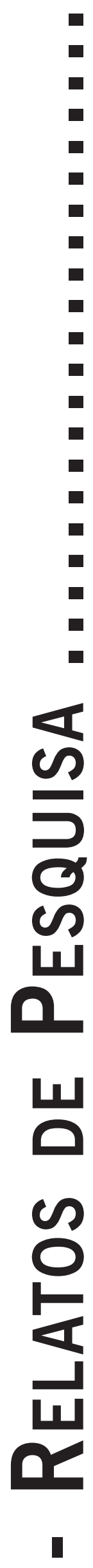




\title{
CONSIDERAÇÕES FENOMENOLÓGICO-HERMENÊUTICAS ACERCA DA SOMATIZAÇÃO NA ADOLESCÊNCIA: UM ESTUDO DE CASO
}

\author{
Phenomenological-Hermeneutical Considerations of Somatization in Adolescence: a Case Study \\ Consideraciones Fenomenológico-Hermenéuticas de Somatización en la Adolescencia: \\ un Estudio de Caso
}

LUANNY TOMAZ BRITO

Ana Karina Silva Azevedo

Luciana Carla Barbosa de Oliveira

\begin{abstract}
Resumo: O objetivo desta pesquisa consistiu em compreender o fenômeno da somatização, à luz da Fenomenologia-Hermenêutica de Martin Heidegger, tomando como base um caso que fora acompanhado pela equipe de saúde de um hospital universitário. Trata-se de um estudo fenomenológico-hermenêutico, de caráter qualitativo, que utilizou como metodologia de investigação o estudo de caso único. Participou da pesquisa uma adolescente de 15 anos de idade, que apresentou como queixa um "entalo na garganta", sendo hospitalizada para tratamento médico e investigação diagnóstica. Foram utilizados como instrumentos de coletas de dados o relatório de atendimento psicológico, elaborado a partir do acompanhamento psicológico realizado com a adolescente, e um roteiro de entrevista semi-aberto. $\mathrm{O}$ estudo mostrou que a somatização pode ser analisada existencialmente com um modo de privação do caráter fundamental de poder-ser do Dasein, como uma carência que sempre se dá em relação ao seu modo de ser-no-mundo-com-os-outros. Evidenciou-se a relevância do contexto psicoterapêutico no favorecimento do encontro da participante consigo mesma, à medida que se disponibilizou um espaço em que ela pode voltar-se à sua experiência e falar de seu sofrimento (expresso na forma de um corporar), reconhecendo e significando-o. Ressalta-se que o desaparecimento do sintoma se deu favorecido pelo contexto psicoterapêutico.
\end{abstract}

Palavras-chave: Somatização; Adolescência; Estudo de caso; Fenomenologia-hermenêutica.

\begin{abstract}
The objective of this research consisted in understanding the phenomenon of somatic illness, in the light of Martin Heidegger's Hermeneutic-Phenomenology, considering a case that had been accompanied by a team of health assistance of a university hospital. This article is a hermeneutic-phenomenological study with qualitative character that used as an investigation methodology the single-case subject. The subject was 15-year-old girl who had been complaining of choking when was hospitalized for medical treatment and diagnosis investigation. A semi-structured interview and a report of psychological service that was elaborated from psychological attendance with the subject were used as instruments of data collection. The present study provides evidence that somatization can be existentially analyzed by a privatization way of the fundamental character from Dasein's view of being as a lack related to her way of being-in-the-world-with-others. Moreover, the study evidenced the importance of psychotherapeutic context in the privilege of the participant in meeting herself, while a space was made available in which the subject could return to her experience and speak about her suffering (expressed in form of bodying forth), recognizing and giving it a significance. Therefore, the study allows for the inference that the psychotherapeutic process led to the disappearance of somatic symptom.
\end{abstract}

Keywords: Somatoform disorders; Adolescent; Case studies; Hermeneutic-phenomenology.

Resumen: El objetivo de esta investigación consiste en la comprensión del fenómeno de la somatización, a luz de la fenomenología-hermenéutica de Martin Heidegger, tomando como base un caso que ha sido acompañado por el equipo de salud de un hospital universitario. Se trata de un estudio fenomenológico-hermenéutico, de carácter cualitativo que usó como metodología de investigación lo estudio de caso único. Ha participado de la investigación una adolescente con 15 años de edad, que presentó como queja un "entalo" en la garganta, cuando fue hospitalizada para recibir tratamiento médico e investigar el diagnóstico. Un informe del servicio psicológico elaborado a partir de la asistencia psicológica con el paciente y uUn itinerario de la entrevista semiabierto fueron utilizados como instrumentos de recopilación de datos. El estudio mostró que la somatizacion puede analizarse a la luz del existencialismo con una manera de privación del carácter fundamental de poder-ser de Dasein, como una falta que siempre siente su manera de ser-en-el-mundo-con-los-otros. También se ha evidenciado la relevancia del contexto psicoterapéutico en el favorecimiento del encuentro de la participante consigo misma, a medida que se ha disponibilizado un espacio en que ella pudo volverse a su experiencia y hablar de su sufrimiento (expreso en la forma de una corporalidad), reconociendo y significándolo. Por consiguiente, es posible inferir que la desaparición del síntoma fue favorecido por el proceso psicoterapéutico.

Palabras clave: Trastornos somatoforme; Adolescente; Estudios de casos; Fenomenología-hermenéutica. 


\section{Introdução}

A ocorrência de sintomas físicos que não possuem causas orgânicas e não são explicados por condições médicas gerais tem sido continuamente relatada ao longo da história da medicina (Coelho \& Ávilla, 2007; Zorzanelli, 2011). Segundo pesquisas atuais, sua prevalência vem crescendo substancialmente, principalmente no âmbito da atenção primária, tornando-se um relevante problema de saúde pública em nível mundial (Fonseca, Guimarães \& Vasconcelos, 2008; Guedes, Nogueira \& Camargo, 2008; Tófoli, Andrade \& Fortes, 2011; Zorzanelli, 2011).

Por outro lado, trata-se de um tema de estudo controverso, atravessado por inúmeras dificuldades, sendo uma destas a utilização de diferentes nomenclaturas em sua abordagem. Coelho e Ávilla (2007), por exemplo, situam o termo somatização como um conceito geral, utilizado para designar fenômenos clínicos variados. Mas outras nomenclaturas têm sido utilizadas, como transtornos mentais comuns, que englobam sintomas depressivos, ansiosos ou somatoformes (Fonseca et al., 2008; Gonçalves \& Kapczinski, 2008); sintomas vagos e difusos (Guedes et al., 2008); doenças sem explicação médica (Zorzanelli, 2011); perturbações de somatização (Tavares, Ferreira \& Fonseca, 2010); perturbações somatoformes (Fabião, Fleming, Silva \& Barbosa, 2010), entre outras.

Fabião et al. (2010) pontua que as diferentes formas de operacionalizar o conceito da somatização e o uso de diferentes sistemas classificativos são considerados os fatores mais relevantes a dificultar a sistematização de resultados de prevalência na população, bem como o desenvolvimento de pesquisas que versem, por exemplo, sobre critérios diagnósticos e intervenções terapêuticas. Existem, portanto, poucos trabalhos empíricos e estudos clínicos que contribuam com novas reflexões e caminhos para se pensar este fenômeno.

Diante de tal contexto, este artigo tem como objetivo compreender a somatização à luz da FenomenologiaHermenêutica de Martin Heidegger, tomando como base o estudo de um caso que fora acompanhado pela equipe de saúde de um hospital universitário. O artigo fora apresentado ao Programa de Residência Integrada Multiprofissional em Saúde - Área de Concentração Saúde da Criança - da Universidade Federal do Rio Grande do Norte, como requisito para obtenção do título de Especialista.

Optou-se por fundamentar o estudo no referencial fenomenológico-hermenêutico, à medida que esta teoria possibilita, por meio de seus fundamentos, uma nova forma de pensar o homem e os aspectos de sua existência. Diversos pesquisadores do campo da saúde, inclusive, têm utilizado a filosofia de Martin Heidegger em seus estudos, buscando refletir e articular novos caminhos para as práticas de saúde, como é o caso de Anéas e Ayres (2011), Galli (2009), Nogueira (2011), Ribeiro (2007), Sales (2008), entre outros.

\section{Somatização: um tema controverso}

Não obstante às ambiguidades e os paradoxos que marcam os estudos acerca da somatização, principalmente quanto aos critérios de classificação e de sistematização, há certo consenso na definição do fenômeno. Escolheu-se aqui o conceito encontrado na publicação de Coelho e Ávila (2007), que define somatização como:

Uma manifestação de conflitos e angústias psicológicos por meio de sintomas corporais. Lipowski (1988) propõe que a somatização "é uma tendência que o indivíduo tem de vivenciar e comunicar suas angústias de forma somática, isto é, através de sintomas físicos que não têm uma evidência patológica, os quais atribui a doenças orgânicas, levando-o a procurar ajuda médica" [grifo do autor]. Acredita que tal tendência geralmente se manifesta em resposta a estresses psicossociais como eventos de vida e situações conflitivas, mas esses pacientes geralmente não conseguem reconhecer que suas angústias têm relação com questões psicossociais e explicitamente negam essa possibilidade (p. 279).

Duval e Oliveira (2010) acrescentam que indivíduos que somatizam possuem a característica de um vínculo diferenciado com a doença que acaba levando-os a buscar inúmeras consultas médicas a fim de tentarem resolver suas dores. "Trata-se de uma via muito mais regredida de expressão, utilizando-se de recursos primitivos, como o corpo, para dar forma e, muitas vezes voz, à experiência humana" (p. 453).

Coelho e Ávilla (2007), por sua vez, afirmam que a somatização não deve ser considerada uma doença específica, mas um processo, um fenômeno, uma manifestação. A categorização diagnóstica dos transtornos que possuem a somatização como uma manifestação geral encontra-se, por sua vez, nos manuais, como a Classificação Internacional das Doenças (CID) e o Manual Diagnóstico e Estatístico de Transtornos Mentais (DSM).

Acerca deste ponto, Zorzanelli (2011) pontua que o campo amplo e controverso dos quadros de somatização aparece hoje em diversas alcunhas nosográficas, dissipadas nos manuais, sendo mais utilizada a denominação "transtorno somatoforme" como classificação diagnóstica geral, que, por sua vez, se divide em subtipos. Na atual edição do CID (Organização Mundial de Saúde de Genebra, 1993), por exemplo, tem-se os seguintes subtipos: transtorno de somatização; transtorno somatoforme indiferenciado; transtorno hipocondríaco; transtorno neurovegetativo somatoforme; transtorno doloroso somatoforme persistente; outros transtornos somatoformes; e transtorno somatoforme não especificado.

Já a atual versão do DSM, lançada em 2013, substituiu o termo "transtornos somatoformes" por "transtornos somático-sintomáticos”, e definiu as seguintes sub- 
categorias: transtorno somático-sintomático; transtorno hipocondríaco ansioso; transtorno conversivo (transtorno neuro-funcional sintomático); fatores psicológicos afetados por uma condição médica; transtorno factício; e transtorno somático-sintomático sem outra especificação. Tais mudanças foram realizadas a fim de remover a sobreposição e confusão de edições anteriores, além de buscar promover a avaliação abrangente dos pacientes, através de diagnósticos mais precisos e oferecimento de um cuidado holístico (American Psychiatric Association, 2013).

Acerca dos sintomas comumente apresentados pelos pacientes, Fonseca et al. (2008) afirma que os transtornos que envolvem a somatização podem se manifestar sob a forma de múltiplos sintomas, como irritabilidade, insônia, crises nervosas, queixas de dor em geral, fadiga, esquecimento; de sintomas gastrointestinais, sintomas conversivos (pseudoneurológicos) e sintomas cardiovasculares (Moreira, Guedes \& Monteiro, 2010).

Em crianças e adolescentes, é particularmente comum o desenvolvimento de queixas de dor (cefaleia, dor abdominal, mialgia e dores nos membros), fraqueza, tontura, sintomas conversivos (quedas inexplicáveis, desmaios, alterações da marcha e alterações sensoriais) e sintomas gastrointestinais (náuseas e vômitos) (Moreira et al., 2010).

Moreira et al. (2010), bem como Tavares et al. (2010), apontam para estudos que revelam uma taxa elevada de casos de transtornos somatoformes na fase da infância à adolescência, sendo mais prevalente na infância tardia e no início da adolescência. O primeiro associa esta prevalência à crise que marca a transição da infância para a adolescência, caracterizada por um período de mudanças em que há expansão dos cenários relacionais do adolescente, aumentando exponencialmente os possíveis estímulos desencadeantes e perpetuadores de estresse, sendo a somatização um resultado desse aumento.

Outro dado importante diz respeito à associação entre a somatização e o sexo feminino. Gonçalves e Kapczinski (2008), em estudo quantitativo desenvolvido numa cidade do interior do Brasil, corroboraram outros estudos, ao concluir que mulheres apresentam mais chance de apresentar transtornos de humor, ansiedade ou somatoformes. Também há evidências da relação dos sintomas de somatização com aspectos socioeconômicos. Desempregados, aposentados por invalidez, vítimas de violência, pessoas de baixa escolaridade e de baixa renda, com dificuldades laborais e donas de casa apresentam os maiores índices no desenvolvimento de somatizações (Fonseca et al., 2008; Tavares et al., 2010; Tófoli et al., 2011).

De qualquer forma, é importante ressaltar que o fato de não haver uma evidência orgânica da ocorrência do sintoma de nenhuma forma diminui o sofrimento dos indivíduos "somatizadores", assim como as suas necessidades de acolhimento e assistência (Fonseca et al., 2008). Todavia, na maioria dos casos, a somatização acaba sendo compreendida como um sinal de incompetência do indi- víduo em superar suas dificuldades, o que indica a inabilidade dos profissionais de saúde em acolher e atender o paciente de forma integral.

A impossibilidade dos profissionais atribuírem uma causa orgânica específica para os sintomas apresentados por esses pacientes desperta nos mesmos um sentimento de desconforto e impotência diante da evidência das limitações da objetividade do modelo biomédico (Guedes et al., 2008). Já os pacientes tendem a se sentir incompreendidos e negligenciados, e por vezes, culpados por não conseguirem lidar com seus problemas.

Duval e Oliveira (2010) afirmam que a dificuldade de compreensão entre médico e paciente explicita de maneira clara o quanto o cuidar de pacientes "somatizadores" passa por falhas nas relações humanas. Similar a esta ideia, Anéas e Ayres (2011) situam dentro do campo do cuidado em saúde, um empobrecimento do aspecto relacional, produto da cisão entre o que é considerado objetivo e o que é considerado subjetivo; há uma valorização do primeiro em detrimento do segundo, à medida que não se considera que o conhecimento científico-tecnológico deve estar a serviço das necessidades humanas.

$\mathrm{O}$ ato médico fundado no cuidado é sempre uma interação entre duas pessoas. Porém, a operação técnica aparece, muitas vezes, separada da relação interpessoal. Mesmo a interação é dividida na relação com o outro, que se consolida apenas com a finalidade da obtenção de informações objetivas, em que se busca o que é relevante para o raciocínio clínico para assim estabelecer uma boa decisão assistencial (Anéas \& Ayres, 2011, p. 652).

Diante de tantas incongruências e dos prejuízos que estas refletem no cuidado em saúde, percebe-se a importância de reconhecer a dimensão humana em sua totalidade e de valorizar as relações interpessoais. É preciso refletir no sentido de que o atendimento de um profissional da saúde não deve ser reduzido à mera aplicação de um conhecimento por meio de procedimentos e técnicas, mas que se trata, fundamentalmente, "de um encontro entre dois sujeitos: um cuidador e um demandante de cuidado" (Guedes et al., 2008, para. 43).

Em se tratando da somatização, considerar a dimensão humana em sua totalidade é conseguir reconhecer a ideia de que o sofrimento somático está intimamente relacionado às experiências, à dinâmica, à história de vida do indivíduo, conforme pontua Duval e Oliveira (2010); e isto implica a necessidade de um espaço terapêutico que extrapole o objetivismo e as generalidades do modelo biomédico; que se assente na relevância do diálogo entre os atores envolvidos; que fomente um olhar para além do sintoma físico; e que respeite a singularidade da experiência daquele que somatiza, possibilitando, dessa maneira, um movimento de mudança e de ressignificação do seu sofrimento. 


\section{Um olhar fenomenológico acerca do adoecimento}

As ciências da natureza estão alicerçadas no paradigma cartesiano, que a partir do princípio da cisão do homem em corpo e mente, desenvolve as noções de sujeito e objeto. É esse paradigma que impulsiona o desenvolvimento de um modelo biomédico positivista na medicina, causalístico e biologizante, pautado "na abordagem do corpo, da doença e da dor como fenômenos físicos que merecem intervenção direta, pragmática e que são passíveis de correção" (Ribeiro, 2007, p. 159).

Heidegger (2008/1986), em oposição a esse modelo, denuncia o abismo que se estabeleceu entre a metodologia científico-natural - produto do paradigma cartesiano - e a compreensão do ser homem em sua totalidade. Inaugura uma compreensão de homem mais ampla, a partir daquilo que considera questão central para a existência humana, o sentido do ser.

Uma parte, por exemplo, o somático do homem, aquilo que é natureza no homem poderia ser pesquisado científico-naturalmente. Diversos métodos de cura muito eficientes da medicina moderna provem dos resultados de tais pesquisas. Mas a maioria admite que não é possível atingir de modo científico-natural o que é central no homem (Heidegger, 2009/1987, p. 58).

Para se referir ao homem em seu ser, numa ontologia fundamental ${ }^{1}$, o filósofo utiliza o termo Dasein ${ }^{2}$. Ele o concebe inicialmente como um ente privilegiado, o único capaz de interrogar o ser, e o único dotado do caráter de poder-ser, marcas da expressão de sua singularidade máxima, tornando qualquer universalização um distanciamento deste seu caráter fundamental (Feijoo, 2011).

A essência do Dasein está fundada em sua existência, num sentido primordial, como uma derivação do termo ek-sistere, que significa "sair", "mostrar-se", "estar fora" (Heidegger, 2008/1986). Desse modo, é um ser-lançado-no-mundo, ou ser-no-mundo, existencial que designa as "múltiplas maneiras que o homem vive e pode viver, os vários modos como ele se relaciona e atua com os entes que encontra e a ele se apresentam" (Spanoudis, 1981, p. 16).

Mas o Dasein é um ser-com, à medida que já sempre é no mundo junto aos outros Daseins. Segundo Spanoudis (1981), ser-com é a característica fundamental e genuína, o como me relaciono, atuo, sinto, penso, vivo com os meus semelhantes.

\footnotetext{
Ontologia fundamental é uma filosofia universal e originária, que tem como tarefa questionar, desvelar e interpretar o sentido do ser. Este filosofar é base de todo conhecimento, inclusive do ôntico, pois refere-se a tudo aquilo que é em seus modos possíveis de ser (Heidegger, 2008/1986).

2 Dasein é um termo alemão usado por Heidegger (2008/1986), que se traduz para o português sob diversas formas: presença, ser-aí, ser-no-mundo, existência. Aqui, optar-se-á por manter o termo original. Por isso, nas citações utilizadas em que constar uma tradução, esta será substituída pelo termo original.
}

À totalidade existencial, de ser-no-mundo-comoutros-daseins-junto-aos-demais-entes Heidegger chama de cuidado (Heidegger, 2008/1986). De acordo com Feijoo (2011), "o Dasein é constitutivamente cuidado, porque ele é os seus modos de ser, e assim, sendo, sempre cuida de si" (p. 38). Esse existencial desdobra-se sob os modos de uma ocupação, que se dá na relação com os entes não dotados do caráter de abertura; e sob a forma de preocupação, que designa a relação entre Daseins.

Essa abertura se articula à linguagem, à medida que seus dois modos originários, a compreensão e a disposição (tonalidade afetiva) são ambos determinados pela fala, a partir da qual a abertura pode se articular em significados e interpretações (Heidegger, 2008/1986).

Como já sendo sempre numa abertura, o Dasein já é lançado em suas possibilidades:

O Dasein já caiu em determinadas possibilidades, e sendo o poder-ser que ele é, já deixou passar tais possibilidades, doando constantemente a si mesmo as possibilidades de seu ser, assumindo-as ou mesmo recusando-as. Isso diz, no entanto, que para si mesmo o Dasein é a possibilidade de ser que está entregue a sua responsabilidade... (Heidegger, 2008/1986, p. 204).

Nesse sentido, o Dasein, entregue à responsabilidade de assumir seu próprio ser, vê-se sempre diante da necessidade de fazer escolhas alicerçada nas inúmeras possibilidades que lhe são abertas no mundo. Ou seja, já sempre "abre o mundo como horizonte no qual os entes lhe vêm ao encontro e lhe requisitam determinados comportamentos" (Feijoo, 2011, p. 38). É, portanto, como ser-no-mundo, como poder-ser, que o Dasein pode constituir-se a si-mesmo e ao mundo, a cada possibilidade assumida ou recusada.

Então, é pelo mesmo caminho que ele está fadado a continuamente perder-se e afastar-se dessas possibilidades, decaindo na impropriedade. Heidegger (2008/1986) afirma que esse é o modo como o Dasein já se encontra na maioria das vezes no mundo, em sua cotidianidade mediana $^{3}$, denominada pelo filósofo de "ditadura do impessoal". O impessoal é caracterizado, principalmente, pelo aprisionamento do Dasein em um dado si-mesmo, privando-o de seu caráter de possibilidade. O impessoal corresponde a tudo aquilo que dita normas, que diz como se é, como se faz, como se vive.

Partindo da ideia da abertura como condição básica do Dasein, é possível, então, pensar ontologicamente o fenômeno do adoecimento e seus impactos na existência humana. Embora não tenha se debruçado amplamente sobre tal questão, Heidegger (2009/1987), em seus Seminários de Zollikon lanças luzes que ajudam a refletir sobre o tema, a partir da compreensão do adoecimento como um fenômeno de privação.

\footnotetext{
3 Cotidianidade mediana refere-se ao modo como o Dasein já se encontra sempre, numa primeira aproximação e na maioria das vezes, em suas atividades comuns (Heidegger, 2008/1986).
} 
O médico pergunta a alguém que o procura: qual é o problema? O doente não é sadio. O ser sadio, o estar bem, o encontrar-se bem não estão simplesmente ausentes, mas perturbados. A doença não é a simples negação da condição psicossomática. A doença é um fenômeno de privação. Toda privação indica a co-pertinência essencial de algo a quem falta algo, que carece ou necessita de algo. Na medida em que os senhores lidam com a doença, os senhores lidam com a saúde, no sentido de saúde que falta e deve ser novamente recuperada (p. 79).

O que o filósofo quer dizer com isso é que a doença não deve ser entendida simplesmente como ausência de saúde, nem deve ser analisada apenas em seu aspecto biológico. Considerando o Dasein em seu estar-lançado-nomundo, pode-se compreender o adoecimento como um modo de privação, mas sempre no sentido de privação do seu caráter básico de poder-ser. No adoecimento, então, o Dasein se compreende como estando numa falta de alternativas de pode-ser. De acordo com Nogueira (2011):

Essa interpretação rompe em definitivo com a base cartesiana da medicina moderna em que a enfermidade é entendida a partir de um corpo físico, e analisada através das modificações de seus constituintes anatômicos, fisiológicos, bioquímicos etc. O corpo e suas mudanças patológicas são apenas uma das inúmeras bases para que o Dasein se compreenda em privação da saúde, sendo sempre essas bases determinadas pelos modos de ser do Dasein (p. 260).

Para a medicina, se o adoecimento é entendido a partir dos órgãos fisiológicos que sinalizam uma patologia, a evidência da saúde, por sua vez, se dá quando não se detecta, por meio de exames, sinais de alterações patológicas nestes órgãos. Considerando apenas o biológico, um homem está vivo à medida que seus os órgãos se mantem em funcionamento. Mas quando se considera o homem em sua totalidade, entende-se que sua vida se dá na dinâmica de ser em um mundo do qual não pode se dissociar. Para o Dasein, pode-se dizer de certa maneira que viver é exercer o seu caráter de poder-ser no mundo. A doença, por conseguinte, "é uma perda de liberdade, uma limitação da possibilidade de viver" (Heidegger, 2009/1987, p. 198), limitação esta de poder-ser dentro de apenas um modo, de uma única possibilidade.

Seguindo seu olhar crítico em relação às ciências naturais, Heidegger examina e discorre sobre a questão da psicossomática. De maneira geral, o filósofo acaba por mostrar que este saber, embora trabalhe na tentativa de uma integração/articulação das dimensões psíquica e somática, ainda não consegue trazer à tona o que é central no ser humano, porque mesmo integrando-as, ainda considera que há duas dimensões distintas que compõem o homem (Heidegger, 2009/1987; Ribeiro, 2007). Com isso, assinala a diferença entre corpo material, objeto das ciências naturais, capaz de ser acessado por meio da mensuração, e corpo, que, para além do corpo material, coloca-se na abertura do ser-no-mundo, compreendendo-se sempre como corporar. Exemplifica:

Alguém enrubesce de vergonha e embaraço. Pode-se medir o enrubescimento? O enrubescer também não pode ser medido, mas sim, a vermelhidão, por exemplo, pela medida do fornecimento de sangue. O enrubescimento é algo psíquico ou somático? Nem um nem outro (Heidegger, 2009/1987, p. 117).

O enrubescimento pode ser compreendido, então, como um corporar, que, é sempre o modo-singular-deser-do-homem-no-mundo. Ou seja, o corporar é um existencial que, como os outros, também é marcado pelo caráter de abertura do Dasein do mundo, indicando o horizonte existencial no qual ele permanece em uma relação direta com o mundo (Ribeiro, 2007). Sendo a corporeidadade sempre co-pertecente ao ser-no-mundo, ela também é co-determinante do relacionamento do Dasein com os outros. Desse modo, retomando o fenômeno do enrubescimento, por exemplo, o enrubescer é um corporar que mostra um estado de ânimo (vergonha, embaraço) diante dos outros (Heidegger, 2009/1987).

Heidegger (2009/1987), então, situa a linguagem como um fenômeno corporal que se dá essencialmente na relação entre Daseins. "Ouvir e falar, isto é, a linguagem em geral, são sempre também um fenômeno corporal" (p. 133). Mas a linguagem não se apenas limita ao ouvir e o falar, pois há também o dizer. "Falar é sempre sonoro, mas eu também posso dizer algo sem som, silenciosamente” (p. 124). O próprio enrubescimento pode ser interpretado com um dizer silencioso da vergonha que se sente diante de alguém.

Retomando a noção de adoecimento como um fenômeno de privação do caráter básico de abertura do Dasein, das suas possibilidades de ser, e o corporar como existencial que expressa esse caráter de abertura do Dasein em relação ao mundo por intermédio do corpo, vislumbra-se um caminho para se pensar o fenômeno da somatização a partir da ontologia heideggeriana. Torna-se possível conceber a somatização, então, como um adoecimento que se mostra através de um corporar (sintoma) e que indica que o Dasein encontra-se em condição de privação, restritiva de seu poder-ser. Assim sendo, é na abertura do ser, por intermédio de um dizer silencioso do corpo, que o Dasein mostra-se de modo privado, evidenciando a falta do exercício da sua condição ontológica de ser sempre um ser de possibilidades.

Por se tratar de um corporar, e não apenas de um sintoma do corpo material, esse adoecimento somático não pode ser mensurado e tratado nos moldes da objetividade médica habitual. Também não deve ser tomado como um fenômeno psíquico, no sentido de algo que se desen- 
rola numa interioridade. Trata-se de considerar qualquer questão relativa ao Dasein, inclusive a somatização, sempre em relação à sua existência no modo de ser-no-mundo-com-os-outros; relação esta que é singular para cada Dasein e, portanto, não generalizável.

\section{Metodologia}

\subsection{Desenho do estudo}

Trata-se de um estudo fenomenológico-hermenêutico, de caráter qualitativo, caracterizado principalmente pelo acesso ao fenômeno da experiência vivida do homem, como aquilo que se mostra em si mesmo, e interpretação do sentido dessa experiência. Nessa metodologia, a linguagem é o instrumento fundamental, pois, conforme Holanda (2006): "na linguagem estão contidos, tanto o questionamento, quanto a sua própria resposta” (p. 368).

Como método de investigação, foi utilizado o estudo de caso único, que, segundo Holanda (2006, p. 367), "refere-se à exploração de um sistema delimitado, partindo de uma coleta de dados detalhada, em profundidade, envolvendo fontes múltiplas de informação”.

A discussão dos resultados foi fundamentada na Fenomenologia-Hermenêutica de Martin Heidegger, à medida que este filósofo deixou aberto um valioso caminho para se pensar as questões relacionadas à existência humana, dentre elas, a saúde e a doença. Ressalta-se, ademais, que esse estudo almeja chegar a uma compreensão ôntico-ontológica da somatização, baseada na analítica existencial do Dasein desenvolvida por Heidegger.

\subsection{Apresentação do caso}

Participou desse estudo Bruna (nome fictício), adolescente de 15 anos de idade, proveniente de uma cidade do interior do Rio Grande do norte, que realizou acompanhamento psicológico durante hospitalização em um hospital pediátrico da cidade de Natal-RN, onde permaneceu durante 16 dias, acompanhada de sua mãe.

A paciente, na sua admissão, apresentara um quadro de desnutrição grave e constipação intestinal aguda, consequências de uma disfagia, denominada pela mesma como um "entalo na garganta", que causava incômodo intenso e a impossibilitava de se alimentar adequadamente (ingeria apenas alimentos líquidos e pastosos).

Diante da falta de evidências orgânicas e condições médicas que justificassem a sintomatologia apresentada, foi solicitado acompanhamento psicológico e psiquiátrico. O médico psiquiatra levantou a hipótese diagnóstica de um transtorno somatoforme, com manifestações clínicas indicativas de um quadro de globus hytericus.

A paciente recebeu alta com solicitação para seguimento ambulatorial com a Gastroenterologia, Psiquiatria e Psicologia. No entanto, ainda durante a hospitalização, relatou o desaparecimento do sintoma do "entalo", reestabelecendo sua alimentação.

\subsection{Procedimentos}

Utilizou-se dois instrumentos de coleta de dados: um relatório de atendimento psicológico, elaborado a partir do acompanhamento psicológico realizado durante hospitalização da paciente e no ambulatório após a alta hospitalar; e um roteiro de entrevista semi-aberto, que partiu da seguinte pergunta disparadora: "Fale sobre sua experiência de adoecimento”. Optou-se pela entrevista semiaberta afim de permitir que Bruna pudesse expressar-se livremente acerca da sua experiência de adoecimento.

Realizou-se uma entrevista com a participante 8 meses após o período de sua hospitalização, sendo conduzida de forma a pontuar no discurso da participante os significados por ela atribuídos à sua experiência de adoecimento e os aspectos existenciais relacionados à sintomatologia que ela apresentou. Tentou-se agendar novos encontros com a participante, que não ocorreram devido à distância entre sua cidade de origem e o local do encontro, e à dificuldade de transporte.

Ressalta-se que durante todo o desenvolvimento do estudo, buscou-se respeitar os princípios éticos que balizam a pesquisa envolvendo seres humanos. O projeto deste estudo foi, por sua vez, submetido ao Comitê de Ética, obtendo aprovação (parecer $n^{0} 437.570$ ). O Termo de Consentimento Livre e Esclarecido, bem como o termo de autorização de gravação de voz, foram devidamente lidos e assinados por todos os envolvidos (participante e responsável), e a entrevista foi realizada apenas na presença de Bruna e do pesquisador, assegurando a confidencialidade das informações e o sigilo quanto à sua identificação.

Por fim, a análise dos dados foi baseada nos quatro passos propostos por Amatuzzi (2001), em que, inicialmente, organiza-se uma síntese dos depoimentos dos participantes, a partir da organização do que foi dito no fluxo desordenado dos encontros; a seguir, realiza-se uma sistematização, identificando e separando as estruturas de sentido reveladas nos relatos; num terceiro momento, estabelece-se o diálogo com outros autores e pesquisadores que também investigaram o fenômeno em questão; e, por fim, comunica-se a pesquisa, estabelecendo-se um novo diálogo com os interlocutores que tiverem acesso a ela.

\section{Resultados e discussão}

Bruna é uma adolescente de 15 anos de idade, habitante da zona rural de uma cidade do interior do Rio Grande no Norte, estudante do ensino fundamental. Reside em casa própria com os pais, 3 irmãos e 3 irmãs, sendo Bruna a mais velha entre as filhas. Embora no prontuário 
conste, segundo relato da mãe, que o casal possui uma prole de 7 filhos, constatou-se, no decorrer do acompanhamento psicológico, a existência de uma oitava filha, nascida antes de Bruna, que, por motivos não relatados, a mãe entregou aos cuidados de um irmão.

De maneira geral, trata-se de uma família com baixo nível socioeconômico. Os pais são agricultores, enquanto os filhos mais velhos não têm emprego fixo, mas contribuem financeiramente com a renda da família quando realizam serviços esporádicos. Além disso, a família é cadastrada no Programa Bolsa Família do Governo Federal.

Embora o objetivo desse estudo seja compreender a somatização a partir de seu caráter singular e não generalizável, torna-se pertinente realizar alguns apontamentos acerca dos resultados aqui expostos com relação aos dados encontrados na literatura geral. Nesse sentido, observa-se que o fato de Bruna ser adolescente é um dado que vai ao encontro das pesquisas de Moreira et al. (2010) e Tavares et al. (2010), pois elas apontam a alta prevalência das queixas somáticas em crianças e adolescentes, principalmente do sexo feminino. Os autores também assinalam, como Fonseca et al. (2008) e Tófoli et al. (2011), uma taxa elevada dos casos de somatização nas populações de baixo nível socioeconômico, corroborando, desse modo, outro dado desta pesquisa.

Durante todo o período da hospitalização, bem como nos encontros ambulatoriais e na entrevista, Bruna sempre se mostrara muito tímida, apresentando excessiva dificuldade de falar a respeito de si própria e de sua vida. Nos dois primeiros atendimentos, realizados ainda no leito, observou-se a presença marcante de sua mãe, que logo que alguém se aproximava, colocava-se ao lado de Bruna e respondia as perguntas dirigidas à filha, enquanto esta se mantinha em seu resoluto silêncio. Nas visitas realizadas à enfermaria, era comum, inclusive, encontrar Bruna sentada no colo de sua mãe, que se referia à filha como "seu bebê". Diante disso, os atendimentos psicológicos passaram a ser realizados em sala individual, apenas com a presença da paciente, visando propiciar um espaço onde ela pudesse expressar-se livremente acerca de si mesma e do que estava vivenciando.

Foram, então, nesses encontros individuais com a psicóloga que Bruna, ainda que com dificuldade e em meio à predominância do silêncio, pôde, pela primeira vez naquela situação de hospitalização, falar sobre o que estava vivenciando, sobre seu adoecimento, sobre sua vida, sobre si mesma. E as primeiras vivências trazidas por Bruna diziam respeito ao que lhe trazia mais sofrimento naquele momento: o seu "entalo".

Faz um ano que eu comecei a sentir esse entalo, mas no começo, dava e passava. De três meses pra cá não passou mais, e ficou mais forte. Antes eu ainda conseguia comer de tudo, agora só como coisa mole, papa, suco, sopa, tudo batido no liquidificador e peneirado $\left(\mathrm{CA}^{4}\right)$.

Conteúdo de fala contido no relato de atendimento psicológico.
Na entrevista, realizada posteriormente à hospitalização, Bruna falou a respeito do início do seu adoecimento:

Começou com um negócio na garganta, sem eu poder comer nada. Eu ficava tipo engasgada... Era uma entalo muito forte... Não doía, só incomodava... Quando eu fiquei internada, acho que fazia tipo um ano que eu sentia esse entalo, mas nos últimos meses foi ficando pior e pior. Eu tentava comer e não conseguia, ficava um negócio ruim na garganta, como se eu tivesse engasgada com alguma coisa. Aí passei a comer só papa, suco, coisas moles $\left(\mathrm{CE}^{5}\right)$.

Fui em um monte de médico... e nada de descobrir. Passava injeção, passava exame, mas não adiantava de nada. Foi quando eu tava sentido muita dor no pé da barriga que me encaminharam pra Natal pra ficar internada. Eu já tava com muita prisão de ventre (CE).

Devido a essa alimentação limitada, Bruna desenvolveu um quadro de desnutrição grave e constipação intestinal aguda, precisando ser hospitalizada para tratamento médico e investigação diagnóstica. Os exames gastrointestinais realizados evidenciaram um quadro de gastrite moderada, mas nada que explicasse a ocorrência do "entalo”. Como a mãe de Bruna relatou à equipe médica que o início do quadro havia coincidido com um término de namoro por decisão dos pais, esta solicitou avaliação psicológica e psiquiátrica.

Em sua avaliação, o psiquiatra levantou a hipótese diagnóstica de um quadro de transtorno somatoforme, provavelmente baseado no CID-10, com manifestação clínica de um sintoma denominado globus hystericus. Segundo o próprio CID-10 (Organização Mundial de Saúde de Genebra, 1993), a principal característica desse transtorno é a presença repetida de sintomas físicos, ainda que os médicos nada encontrem de anormal e constatem que os sintomas não têm nenhuma base orgânica. Então, não é possível uma explicação médica para os sintomas, bem como, consequentemente, um alívio para o sofrimento e as preocupações do sujeito doente pela via do saber médico.

Com relação ao globus hystericus, Kahrilas e Smout (2012) afirmam tratar-se da "percepção de um nódulo ou plenitude na garganta sentidos independentemente da deglutição" (p. 12), que ocorre muitas vezes no cenário de distúrbios de ansiedade ou em obsessivos-compulsivos, o que se leva a inferir a relação do globus hystericus com questões psicológicas. Entretanto, se por um lado, esse dado vai ao encontro da literatura, que pontua os sintomas gastrointestinais como um dos mais comumente apresentados por crianças e adolescentes na somatização (Moreira et al., 2010), por outro, a definição de globus hystericus não se encaixa precisamente no quadro da paciente, pois ela apresentou uma dificuldade de deglutição associada

Conteúdo de fala contido na transcrição da entrevista. 
ao entalo referido, e segundo Kahrilas e Smout (2012), a sensação de globus hystericus se dá independentemente da deglutição, como afirmado acima.

Tomando como base as reflexões de Heidegger (2009/1987), é possível compreender ontologicamente o adoecimento de Bruna como um fenômeno de privação do seu caráter essencial de poder-ser no mundo; ou seja, na condição de doente, Bruna vivenciou uma limitação de suas possibilidades de ser. Ao plano ôntico, Nogueira (2011) denomina a privação de saúde de "padecimento", palavra que destaca a tonalidade afetiva (disposição) do Dasein na privação sob a forma de um sofrimento, de um mal-estar. Observou-se no discurso de Bruna esse sofrimento causado pela sua condição de estar-doente:

Esse entalo é horrível, eu não aguento mais. Quero muito que isso saia da minha vida. Antes dele aparecer, eu era alegre, saía, me divertia. Agora eu não tenho mais nem vontade de passear. Minhas primas dizem que tô muito chata. E eu tô mesmo (CA).

Dessa maneira, Bruna, devido ao entalo que sentia, foi gradativamente adoecendo e, por conseguinte, se privando das coisas que fazia em sua cotidianidade mediana: da incapacidade de se alimentar à impossibilidade de sair, de se divertir, de estar-com-os-outros.

O entalo era ruim demais. Eu não podia fazer as coisas que eu queria... Não podia comer nada do que eu queria, nem confeito, nem chocolate, pipoca, eu não comia nada disso... Mãe mandava eu comer arroz, feijão, carne, mas eu não conseguia (CE).

Faz um tempão que não saio com minhas primas, que não vou na lan house, que não ando de bicicleta, que não consigo mais fazer essas coisas que eu gosto... Porque sinto fraqueza demais, e não dá vontade de fazer nada (CA).

Sobre isso, Nogueira (2011) aponta que as restrições às possibilidades de ser do Dasein tomam a forma da impotência, comunicados em formas similares as que se evidenciaram na fala de Bruna: "não posso mais fazer...; não posso mais me divertir com...; não mais suporto; tive de deixar de...” (p. 265). Nota-se, tanto nesse trecho, como nas falas de Bruna, que a privação do poder-ser é sempre referida ao ser-no-mundo, ou seja, aponta para uma deficiência, uma carência que se dá na relação $D a-$ sein-mundo.

É possível interpretar fenomenologicamente o "entalo" de Bruna como um fenômeno do corpo, como um corporar, que, retomando a revisão teórica deste trabalho, compreende-se como linguagem, como um dizer. Este dizer, por sua vez, indica que, mesmo numa condição de privação de possibilidades, a abertura do ser do Dasein ainda opera, abrindo-se e mostrando por meio do corpo sua carência de exercer seu poder-ser. Nesse sentido, Bruna, não conseguindo dizer verbalmente, disse por outra via do corpo, que se encontrava incapacitada de exercer plenamente sua liberdade existencial.

Como já situado, a privação do poder-ser de Bruna indica uma carência que se dá na relação dasein-mundo, especialmente, no seu ser-com-os-outros. Em vários momentos dos encontros com Bruna, observou-se a presença dos outros em sua fala.

Os meninos mexiam comigo, chamavam eu de Olivia Palito. Minhas amigas e minhas primas diziam que eu tava chata, e eu tava mesmo. Eu não saía, minha mãe não deixava, ficava preocupada, aí eu não tinha vontade de sair... (CE)

Todo mundo dizia que eu tava muito magra, roupa nenhuma prestava em mim. Fui pra praia uma vez com minha família no ano novo, e fiquei com vergonha de tomar banho no mar, nem aproveitei (CE)

Minha mãe diz que eu sou muito nervosa. E eu acho que sou mesmo. Quanto tô nervosa, sinto minhas mãos e meus pés gelados. Dá uma agonia no coração (CA).

Tenho vontade de ser modelo. Já desfilei na cidade e na escola e todo mundo diz que eu tenho jeito. Minha prima diz que ser modelo é bom, porque fica famosa, anda de carro, tira fotos (CA).

Diante dessas falas, nota-se uma grande importância que a opinião das outras pessoas tem para Bruna, que, inclusive, deixou de vivenciar certas situações por solicitação ou por vergonha dos outros. Percebe-se que a opinião "de todo mundo" tinha peso até mesmo quando se tratava de seus desejos e planos futuros. Em seu falar, Bruna evidenciou sua decadência no modo impessoal de ser-com-os-outros-no-mundo.

$\mathrm{Na}$ cotidianidade mediana, sendo-com-os-outros, o Dasein fatalmente já se encontra no âmbito da impessoalidade, dissolvido na convivência com os outros, e afastado de seu existir singular, em prol do público, do "todo mundo" (Heidegger, 2008/1986). Assim, perdida em sua impessoalidade, Bruna é levada a agir de acordo com o que dizem ser certo ou errado, e toma como sendo sua a fala das outras pessoas, delegando a outrem sua existência.

Ainda com relação à impessoalidade de Bruna, há um fato em especial que chamou atenção durante todo o acompanhamento psicológico: a relação dela com sua mãe. Já foi dito acima que, nos primeiros encontros com Bruna, era a mãe quem respondia as perguntas dirigidas à filha, além de constantemente colocá-la no colo, e chamá-la de "meu bebê". Na entrevista, questionada a respeito desse seu silêncio na presença da mãe, Bruna respondeu com a seguinte frase: "porque ela fala por mim" [sic]. Foi 
possível observar muitas situações que se configuraram como decisão ou vontade da mãe, mas que Bruna relatara como sendo também decisão ou vontade sua: o término do namoro, a falta de vontade de sair de casa na época do adoecimento, entre outras.

Eu tava namorando o Pedro (nome fictício). No dia que fui internada, fazia poucos meses que tinha acabado. Era um termina e volta, aí acabou de vez. Mãe disse pra mim que era melhor acabar logo de uma vez, porque tinha que pensar na minha saúde e nos meus estudos (CE).

Eu gostava dele, era bom. Mas foi melhor terminar porque tava muito enrolado. Não queria ter terminado, mas foi melhor assim (CE).

Nesse sentido, pode-se compreender que entre Bruna e sua mãe, nos modos da convivência cotidiana, foi se estabelecendo uma relação de preocupação que Heidegger (2008/1986) designa como dominadora e substitutiva. Nela, a mãe retirou de Bruna seu "cuidado", tomando dela a responsabilidade por seu ser e tornando-a dependente. Heidegger chega a afirmar ainda que nesse modo de preocupação, "o outro pode tornar-se dependente e dominado mesmo que esse domínio seja silencioso e permaneça encoberto" (p. 178).

Esse modo de preocupação é umas das suas duas possibilidades extremas (fora elas, existem outras infinitas variações possíveis). A outra possibilidade extrema de preocupação é a preocupação antepositiva e liberadora, em que um Dasein se antecipa ao outro não para lhe dominar, mas para liberá-lo em seu "cuidado”, em sua liberdade para assumir propriamente seu poder-ser no mundo (Heidegger, 2008/1986).

Em suma, Bruna deixou-se dominar pela alienação e pela acomodação, abrindo mão de suas possibilidades de ser para se fechar em um "si-mesmo" determinado pelos outros (principalmente pela mãe), perdendo-se do seu ser-si-mesmo mais próprio. Esse modo de ser no impessoal revela algo como uma fuga do Dasein de si mesmo. Dessa maneira, “é justamente daquilo que 'foge' que o Dasein corre atrás. Somente à medida que, através de sua abertura constitutiva, o Dasein se coloca essencialmente diante de si mesmo é que ele pode fugir de si mesmo" (Heidegger, 2008/1986, p. 251).

O adoecimento de Bruna é, pois, um sinal de extravasamento, de um excesso de impessoalidade. De tanto fugir de si mesma e se deixar dominar pelos outros, o adoecimento mostra que ela própria não suportava mais essa condição de privação, como ela evidenciou em sua fala: "eu não aguento mais... quero muito que isso saía da minha vida" [sic]. Seu "entalo", muitas vezes relatado como um engasgo, possivelmente dizia do seu engasgo diante de tantas opiniões e decisões sobre ela própria. Bruna não conseguia falar, não conseguia comer, pois ela estava cheia das outras pessoas. O silêncio que marcou o início dos encontros era, pois, o silêncio de alguém que, por ter se entregado ao domínio de outrem, nada sabia e nada conseguia dizer ao seu próprio respeito, o que apareceu recorrentemente nos atendimentos clínicos através da seguinte fala: "eu não sei falar de mim" [sic].

Esse movimento na direção do impessoal é possível justamente pelo Dasein já e desde sempre estar em jogo com o seu ser na abertura e, por isso, pode a cada momento operar uma escolha: perder-se ou ganhar-se ao assumir propriamente suas possibilidades, seu poder-ser mais próprio.

Quando o Dasein descobre o mundo e o aproxima de si, quando abre para si mesmo seu próprio ser, este descobrimento de 'mundo' e esta abertura do Dasein se cumprem e realizam uma eliminação das obstruções, encobrimentos, obscurecimentos, como um romper das distorções em que o Dasein se tranca contra si mesmo (Heidegger, 2008/1986, p. 187).

É exatamente este rompimento que é possível na relação de preocupação liberadora. É nesta posição que o psicólogo deve estar para que propicie, pela fala, uma expressão de abertura em que o paciente possa escutar seu poder-ser-si-mesmo mais próprio e exercer sua existência autenticamente.

Isso acontece a partir do que Heidegger (2008/1986) chama de clamor ${ }^{6}$ da consciência, momento de apropriação no qual o Dasein é atravessado por uma interpelação, que afasta a impessoalidade e o convoca a assumir o seu poder ser-mais próprio. O clamor, é sem palavras, é silencioso e, em sua maioria, não é escutado pelo $D a-$ sein, pois "justamente não é e nunca pode ser algo planejado, preparado ou voluntariamente cumprido por nós mesmos” (p. 354). Então, não é algo com que o paciente possa operar, como uma potência sua, ou mesmo que ele possa ter acesso tematicamente, no sentido de simplesmente querer isso, mas que ocorre e pode manifestar seus efeitos por uma mudança de atitude e, consequentemente, de fala.

A mudança pode ser despertada no trabalho psicológico, e quanto a Bruna, nota-se uma mudança significativa no seu existir enquanto ser-no-mundo e ser-comos-outros:

Eu me sinto muito melhor. Hoje eu posso sair, posso tomar banho na praia (CE).

Agora eu tenho saído muito, com minha irmã, minhas primas, minhas amigas... A gente vai pra um monte de lugar (CE).

\footnotetext{
6 Traduzido na obra utilizada como "apelo" (Heidegger, 2008/1986). Aqui, optar-se-á pela expressão "clamor".
} 
Eu achava que eu queria ser modelo, mas eu não quero mais. Ser modelo é muito ruim, viaja muito, fica longe da família. Também tem que ser muito magra, e eu gosto de como eu tô agora, quero encher mais (CE).

Além disso, e aliado a essa mudança - uma vez que na abertura compreensiva aqui proposta do Dasein em sua totalidade, pôde-se abrir o sintoma físico ao aspecto existencial manifesto no corporar como fala -, há o desaparecimento do sintoma, que ocorreu quando a mesma ainda estava hospitalizada. Na entrevista, ela precisou o momento em que se deu conta de que não era mais acometida pelo "entalo".

Um dia, minha mãe disse que se eu comesse, ela ia mandar bota aparelho no meu dente, mas mesmo assim, eu não consegui comer. Aí um outro dia, naquele dia que falei com tu, minha tia chegou lá, foi pegar comida e mandou eu comer. Minha mãe apostou comigo como eu não comia, aí eu peguei e comi (...) Não senti nada não, a comida desceu (CE).

Nota-se no relato o momento repentino com que se deu a supressão do "entalo", bem como a posição da mãe na situação, que, se em relatos anteriores mostrava-se como uma presença dominadora que tirava de Bruna seu "cuidado", neste, aparece como alguém que Bruna desafia, ao assumir uma escolha que se contrapôs à fala da mãe.

Bruna refere-se ao acompanhamento psicológico como uma experiência positiva para ela, que apesar de toda a dificuldade que tinha para falar, e do incômodo que lhe causava os minutos de silêncio nas sessões, viu no espaço psicoterapêutico uma oportunidade para se expressar, para desabafar.

Eu conversava contigo... E era bom conversar, desabafar. Logo quando cheguei, fiquei com medo de fazer as lavagens, e tu foi lá conversar com eu. Quando fiz o exame da garganta também (CE).

Obviamente, não foi sem sofrimento que se desenrolou o trabalho psicológico de Bruna, mas propiciou a ela, partir do movimento de abertura ao ser, a significação da sua vivência de adoecimento, uma mudança de posição com relação ao seu modo de ser-no-mundo-com-os-outros.

Nogueira (2011), ao alicerça-se as reflexões heideggerianas, utiliza a expressão "reatamento" para designar o momento em que o Dasein emerge de sua submissão ao impessoal, reparando sua falta de escolha. Afirma que esse caminho se dá alicerçado em diversos constituintes existenciais, dentre eles, o clamor da consciência, já mencionado anteriormente. Nesse sentido, é possível compreender o momento da "decisão de comer" como um reatamento, um encontro de Bruna novamente com seu si-mesmo próprio.
Portanto, compreende-se a relevância do contexto psicoterapêutico no favorecimento do encontro de Bruna consigo mesma, à medida que se disponibilizou um espaço em que ela pode voltar-se para a sua existência e falar de seu sofrimento (expresso na forma de um corporar), reconhecendo e significando-o. Encontrando guarida na relação de cuidado estabelecida com a psicóloga, que lhe acompanhou e se dispôs a escutá-la na abertura de seu ser, Bruna, a partir daquele momento da decisão de comer, conseguiu romper com a impessoalidade e assumir seu ser-si-próprio, refazendo-se, naquele instante, em sua totalidade existencial.

\section{Considerações finais}

Retomando as discussões elaboradas no desenrolar desta pesquisa, é possível concluir, de modo geral, que a somatização configura-se como um campo controverso e obscuro dentro da ciência médica, refletindo diversas incongruências teóricas. Entretanto, é reconhecida a existência e a importância das generalizações e delimitações objetivas, a partir das quais se torna possível sistematizar dados, definir critérios diagnósticos e intervenções terapêuticas, bem como estabelecer resultados de prevalência na população.

Por outro lado, é necessário que se construam novas perspectivas que propiciem uma compreensão mais ampla e complexa acerca da somatização. Nesse sentido, este artigo propôs uma compreensão desse fenômeno à luz da Fenomenologia-Hermenêutica de Martin Heidegger, filósofo que traz em sua ontologia uma desconstrução e reconstrução das concepções de homem e mundo da tradição, nas quais está enraizado todo o conhecimento ôntico. Ele desenvolve uma analítica da existência humana e do seu mundo, tendo como questão norteadora o sentido do ser.

A partir das reflexões que partiram da experiência da participante e da ontologia heideggeriana, pode-se compreender que a somatização, para além de uma doença do corpo material, ou de um problema psíquico, deve ser analisada existencialmente com um modo de privação do caráter fundamental de poder-ser do Dasein, como uma carência que sempre se dá em relação ao seu modo de ser-no-mundo-com-os-outros. Nesse sentido, o adoecimento somático constitui uma experiência singular para cada Dasein que a vivencia. Entendemos que oferecer esse olhar para a queixa que ali se apresenta é de grande contribuição para compreender o sofrimento humano, que nesta forma de comunicação, não encontra nomeação nos protocolos médicos e de saúde. Este sofrimento, expresso no corporar, reflete a caminhada existencial, o modo-de-ser-no-mundo de cada sujeito, indivíduo, Dasein.

Diante de tal singularidade, percebe-se que as técnicas interventivas pautadas no objetivismo e determinis- 
mo não dão conta de abarcar um fenômeno que remete à complexidade do existir humano. Isso reflete, por sua vez, na importância do processo psicoterapêutico, à medida que nele configura-se essencialmente um espaço de fala e escuta, ou seja, um espaço de abertura ao ser. Como exemplo, retoma-se a experiência de Bruna, que a partir do reconhecimento de seu sofrimento, expresso na forma de sintoma, pode se ouvir e voltar-se para a sua existência, favorecendo ao encontro do sentido de si. Ressalta-se que o desaparecimento do sintoma se deu em um contexto psicoterapêutico.

Além da compreensão sobre o fenômeno da somatização aqui desenvolvida, observa-se que as reflexões de Heidegger podem trazer inúmeras contribuições ao campo da saúde. Embora atualmente preconize um modelo que considera os aspectos biopsicossociais do indivíduo, este campo ainda capenga na predominância do paradigma biomédico, refletindo a dificuldade por parte dos profissionais em lidar com os aspectos subjetivos do paciente, que, por conseguinte, resulta em práticas "desumanizadas" e "reducionistas".

Sabe-se, entretanto, que não se configura como fácil a tarefa de apropriar-se da ontologia fundamental do filósofo, dada sua extensão e complexidade. Por outro lado, acredita-se que, embora trabalhosa e angustiante, esta empreitada se constitui em uma verdadeira jornada para a compreensão de nossa existência, e abre um campo incrivelmente vasto para a reflexão, o questionamento e a construção de novos conhecimentos, inclusive para as ciências exatas, à medida que já se conhece suas competências e limitações.

\section{Referências}

Amatuzzi, M. M. (2001). Pesquisa Fenomenológica em Psicologia. Em M. A. T. Bruns \& A. F. Holanda (Orgs.). Psicologia e pesquisa fenomenológica: Reflexões e perspectivas (p. 15-22). São Paulo: Ômega.

American Psychiatric Association. (2013). Diagnostic and statistical manual of mental disorders: DSM-V (5th Ed.). Arlington, VA: Author.

Anéas, T. V., \& Ayres, J. R. C. M. (2011, junho/setembro). Significados e sentidos nas práticas de saúde: A ontologia fundamental e a reconstrução do cuidado em saúde. Interface - Comunicação, saúde e educação, 15 (38), 651-662.

Coelho, C. L. S. \& Ávila, L. A. (2007). Controvérsias sobre a somatização. Revista de Psiquiatria Clínica, 34 (6), 278-284.

Duval, M. R., \& Oliveira, S. L. (2010). Medicina psicossomática e a política de humanização do SUS: Desconforto na contemporaneidade. O Mundo da Saúde, São Paulo, 34 (4), 451-456.

Fabião, C., Silva, M. C., Fleming, M., \& Barbosa, A. (2010). Perturbações somatoformes: revisão da epidemiologia nos cuidados primários de saúde. Acta Médica Portuguesa, 23 (5), 865-872.
Feijoo, A. M. L. C. (2011). A existência para além do sujeito: A crise da subjetividade moderna e suas repercussões para a possibilidade de uma clínica psicológica com fundamentos fenomenológico-existenciais. Rio de Janeiro: Edições IFEN: Viera Verita.

Fonseca, M. L. G., Guimarães, M. B. L., \& Vasconcelos, E. M. (2008, junho/setembro). Sofrimento difuso e transtornos mentais comuns: Uma revisão bibliográfica. Revista da APS, 11 (3), 285-294.

Galli, L. M. P. (2009). Um olhar fenomenológico sobre a questão da saúde e da doença: Cura do ponto de vista da GestaltTerapia. Estudos e pesquisas em Psicologia, 1, 59-71.

Gonçalves, D. M., \& Kapczinski, F. (2008, junho). Transtornos mentais em comunidade atendida pelo Programa Saúde da Família. Caderno de Saúde Pública, 24 (7), 1641-1650.

Guedes, C. R., Nogueira, M. I., \& Camargo Jr., K. R. (2008). Os sintomas vagos e difusos em biomedicina. Ciência e Saúde Coletiva, 13 (1), 135-144.

Heidegger, M. (2008). Ser e tempo. (M. Schuback, Trad.) (3. ed.). Petrópolis: Vozes; Bragança Paulista: Editora Universitária São Francisco. (Original publicado em 1986).

Heidegger, M. (2009). Seminários de Zollikon. (M. Boss, Ed.) (G. Arnhold \& M. F. A. Prado., Trads.) (2. ed. rev.). Petrópolis: Vozes; Bragança Paulista: Editora Universitária São Francisco. (Original publicado em 1987).

Holanda, A. (2006). Questões sobre pesquisa qualitativa e pesquisa fenomenológica. Análise Psicológica, 24 (3), 363-372.

Kahrilas, P. J., \& Smout, A. J. P. M. (2012). Transtornos esofágicos. Arquivos de Gastroenterologia, 49, 11-10.

Moreira, L., Guedes, R., \& Monteiro, P. (2010). O corpo e a saúde mental. Revista do Hospital de Crianças Maria Pia, XIX (1), 8-13.

Nogueira, R. P. (2011). Extensão fenomenológica dos conceitos de saúde e enfermidade em Heidegger. Ciência e Saúde Coletiva, 16 (1), 259-266.

Organização Mundial de Saúde de Genebra. (1993). Classificação de Transtornos mentais e de comportamento da CID-10: Descrições clínicas e diretrizes diagnósticas (10. ed.). Porto Alegre: Artes Médicas.

Ribeiro, E. C. (2007). A questão da psicossomática à luz da fenomenologia-existencial e da abordagem gestáltica. Revista IGT na Rede, 4 (7), 158-166.

Sales, C. A. (2008, outubro/dezembro). O ser-no-mundo e o cuidado humano: Concepções heideggerianas. Revista de Enfermagem da UERJ, 16 (4), 563-568.

Spanoudis, S. (1981). A todos que procuram o próprio caminho. Em M. Heidegger, Todos nós... Ninguém: Um enfoque fenomenológico do social (p. 9-24). São Paulo: Moraes.

Tavares, H. B., Ferreira, P. D., \& Fonseca, H. (2010, janeiro/ fevereiro) Perturbação de somatização: Uma patologia prevalente em adolescentes. Acta Pediátrica Portuguesa, 41 (1), 33-37. 
Tófoli, L. F., Andrade, L. H., \& Fortes, S. (2011, maio). Somatização na América Latina: Uma revisão sobre a classificação de transtornos somatoformes, síndromes funcionais e sintomas sem explicação médica. Revista Brasileira de Psiquiatria, 33 (1), 59-69.

Zorzanelli, R. T. (2011). Sobre os diagnósticos das doenças sem explicação médica. Psicologia em estudo, 16 (1), 25-31.

Luanny Tomaz Brito - Psicóloga graduada pela Universidade Federal do Maranhão, Especialista em Saúde da Criança pelo Programa de Residência Integrada Multiprofissional da Universidade Federal do Rio Grande do Norte. Mestranda do Programa de Pós-Graduação em Psicologia da Universidade Federal do Maranhão. E-mail: luanny-tomaz@hotmail.com

Ana Karina Silva Azevedo - Graduada em Psicologia, com Mestrado e Doutorado pela Universidade Federal do Rio Grande do Norte. Atualmente é professora da Universidade Federal do Rio Grande do Norte.

Luciana Carla Barbosa de Oliveira - Possui graduação em Psicologia, com Especialização em Psicologia da Saúde: Desenvolvimento e Hospitalização e Doutorado em Ciências da Saúde pela Universidade Federal do Rio Grande do Norte. Docente do curso de Psicologia do Centro de Ensino FACEX - UNIFACEX. Tutora e Preceptora da Residência Integrada Multiprofissional em Saúde na Atenção à Criança e da Residência Integrada Multiprofissional em UTI no Núcleo de Saber em Psicologia - HUOL/UFRN. Psicóloga Hospitalar do HUOL/UFRN. Endereço institucional: Hospital Universitário Onofre Lopes (HUOL/UFRN). Av. Nilo Peçanha, 620 - Petrópolis. CEP: 59.012-300. Natal/RN.

Recebido em 11.03.2014

Primeira Decisão Editorial de 23.08.2014

Segunda Decisão em 22.03.2015

Aceito em 27.04.2015 